\title{
CONTRIBUIÇÕES DE ELEMENTOS DO CONSTRUTIVISMO E DA MEDIAÇÃO DA INFORMAÇÃO PARA A INCLUSÃO DIGITAL DE IDOSOS
}

\author{
CONTRIBUCIONES DE LOS ELEMENTOS DEL \\ CONSTRUCTIVISMO Y DE LA MEDIACIÓN DE INFORMACIÓN \\ PARA LA INCLUSIÓN DIGITAL DE LAS PERSONAS MAYORES
}

\author{
Fernando Luiz Vechiato - vechiato2004@yahoo.com.br \\ Doutorando em Ciência da Informação pelo Programa de Pós-Graduação em \\ Ciência da Informação da UNESP, Campus de Marília \\ Professor Colaborador do Departamento de Ciência da Informação da \\ Universidade Estadual de Londrina, UEL \\ Silvana Aparecida Borsetti Gregorio Vidotti - vidotti@marilia.unesp.br \\ Doutora em Educação \\ Professora do Programa de Pós-Graduação em Ciência da Informação \\ da Unesp de Marília
}

\section{Resumo}

Com o aumento da expectativa de vida da população mundial, os estudos acerca do envelhecimento humano estão se desenvolvendo de maneira considerável. Dentre esses estudos, destacamos a interação entre os idosos e as tecnologias de informação e comunicação, as quais podem facilitar a realização de atividades cotidianas por esses indivíduos. Nesse sentido, objetivamos investigar a aplicação de elementos construtivistas nos cursos de informática oferecidos para a Universidade Aberta à Terceira Idade - UNATI - UNESP - Campus de Marília, contribuindo para a inclusão digital dessa comunidade. Esses elementos foram refletidos tendo como foco o papel do professor-mediador no processo de ensino-aprendizagem. Verificou-se que a maioria dos elementos construtivistas já está sendo aplicada nesse universo, porém algumas alterações precisam ser realizadas, tendo em vista ampliar as possibilidades de ensino e permitir que os alunos tenham maior autonomia na busca e uso de informações na Web.

\section{Palavras-chave}

Inclusão digital. Idosos. Construtivismo. Tecnologias de Informação e Comunicação. Mediação da Informação. 


\section{INTRODUÇÃO}

Convivemos, atualmente, com a evolução das tecnologias de informação e comunicação (TIC), em especial da Internet, que facilita sobremaneira as ações cotidianas dos indivíduos. A rapidez com que as informações são veiculadas contribui efetivamente para sua disseminação / divulgação e dinamiza a comunicação que ocorre sem barreiras espaciais ou temporais. Além disso, permite aos seus usuários um conhecimento vasto e, muitas vezes, superficial de mundo, devido à quantidade e à variedade de informações disponíveis.

Não devemos ter uma visão ilusória de que todos os cidadãos estão inseridos nesse contexto, bem como estamos longe de atingir a democratização do acesso à informação proposta pela sociedade da informação devido, sobretudo, as questões culturais, econômicas e sociais.

Nesse cenário, focamos um público específico - os idosos - que, por um lado, são beneficiados com os avanços da medicina que contribuem para o aumento da expectativa de vida da população mundial e, por outro, sofrem com o preconceito em uma sociedade que cultua a estética e a jovialidade.

Entendemos que as TIC podem auxiliar os idosos a resgatarem sua identidade e imagem quando se tornam ativos, dinâmicos e críticos na busca e uso de informações para a vida cotidiana, além de se relacionarem com as pessoas em um momento da vida no qual a tendência é o isolamento.

Esse trabalho é derivado de uma proposta de capacitação de idosos para o uso das TIC desenvolvida junto aos alunos da Universidade Aberta à Terceira Idade (UNATI) - UNESP - Campus de Marília desde 2006 a partir da investigação das reais necessidades desse grupo, conforme detalhado por Vidotti et al. (2009). Tendo em vista que essa proposta poderá viabilizar a inclusão digital e social desses sujeitos, objetivamos identificar elementos do construtivismo aplicados à educação a serem utilizados no processo de mediação no ensinoaprendizagem das TIC.

\section{IDOSO, TECNOLOGIA E SOCIEDADE}

Sabemos que, em paralelo à diminuição da taxa de natalidade, a expectativa de vida da população mundial vem aumentando consideravelmente. Isso se deve, principalmente, aos avanços da medicina e à importância atribuída às ações preventivas que possibilitem às pessoas terem mais qualidade de vida, o que contribui para a longevidade. A Geriatria, campo da Medicina que investiga as patologias do envelhecimento humano, atua, com freqüência, em conjunto com a Gerontologia, área esta que

[...] visa estudar as mudanças típicas do processo do envelhecimento e de seus determinantes biológicos, psicológicos e socioculturais. É um campo multiprofissional e multidisciplinar. Embora a Gerontologia envolva muitas disciplinas, a pesquisa repousa sobre um eixo formado pela Biologia, pela Psicologia e pelas Ciências Sociais (CALDAS, 2006, p.18). 
Embora exista uma evolução visível nos estudos sobre envelhecimento humano por conta do aumento da expectativa de vida, sabemos que, em muitos aspectos, não ocorre preocupação efetiva com os idosos. Mesmo com a conquista do Estatuto do Idoso ${ }^{1}$, questões relacionadas à identidade e à imagem do idoso perante a sociedade ainda não são resolvidas. Se, por um lado, os idosos tiveram várias conquistas e as próximas gerações se beneficiarão delas, por outro sua imagem é muitas vezes deflagrada pela mídia quando cultua em demasia a estética e a jovialidade.

Dulce Whitaker (2007), professora universitária aposentada, relata, baseando-se em suas próprias vivências, como o idoso foi perdendo o poder e sua imagem na sociedade brasileira. Relaciona o idoso de hoje, aposentado, e o idoso de alguns anos atrás, proprietário de um pequeno ou um grande negócio, o qual possuía certo poder que, conseqüentemente, o apontava para uma imagem de pessoa sábia e líder supremo no clã familiar. A autora elenca alguns motivos que direcionaram a essas mudanças:

- O país se industrializou e se modernizou;

- Chegaram as grandes corporações multinacionais e os pequenos negociantes foram esmagados pela competição que não conseguiram enfrentar;

- Mulheres e jovens se assalariaram, indo trabalhar fora do clã familiar;

- A família encolheu, reduzindo-se a marido, mulher e filhos, com alta porcentagem de mães sozinhas (WHITAKER, 2007, p.5758).

Ao longo dos anos, o idoso foi perdendo o poder por conta das modificações sociais, culturais e econômicas. Vemos, constantemente, a falta de preocupação das pessoas com os idosos, seja em supermercados, ônibus urbanos, filas de banco que, embora preferenciais, não resolvem o problema da espera. O idoso não é incapaz, porém necessita de cuidados específicos, como as pessoas em outras faixas etárias e/ou com condições específicas. Para Garcia (2001, p.18),

$\mathrm{Na}$ maioria dos países em desenvolvimento não existe uma preocupação com o envelhecimento da população, motivo esse compreensível devido ao crescimento demográfico acelerado, êxodo rural muito acentuado, entre outros fatores. Apesar das pesquisas científicas terem conseguido ampliar um pouco mais o tempo da existência humana, a sociedade não acompanhou esse padrão de longevidade. Com isso, a situação dos idosos tem-se agravado progressivamente, pois os poderes públicos não dispõem de recursos suficientes para elaborar uma política social que atenda às necessidades reais deste grupo etário.

Nesse contexto, a tecnologia pode facilitar a vida dos idosos, possibilitando novas alternativas para a realização de atividades cotidianas. Fazer compras e pagar contas pela Internet, por exemplo, pode ser mais confortável do que se

1 Disponível em: <http://www.planalto.gov.br/ccivil_03/LEIS/2003/L10.741.htm>. Acesso em 04 nov. 2009. 
deslocar para um determinado ambiente físico, considerando que os idosos possuem limitações físicas e cognitivas decorrentes do processo natural de envelhecimento humano.

É importante ressaltar que os idosos de hoje acompanharam paralelamente o surgimento e evolução das TIC, porém particularmente a Web, serviço da Internet que evolui progressivamente desde seu surgimento em meados da década de 1990, é uma ferramenta que muitos idosos nem sabem da sua existência. Aqueles que atuaram profissionalmente podem até ter tido algum contato com os primeiros computadores, mas a Web surgiu em um momento em que muitos já haviam se aposentado, não tendo a oportunidade de aprender a utilizar esse serviço.

A relação idoso-computador é um tema que está começando a ser desenvolvido em pesquisas científicas. Nessa perspectiva, a Ciência da Informação tem muito a contribuir com esse público específico, visto que os idosos possuem necessidades específicas, buscam informações nas mais variadas fontes e estão interessados em utilizar os ambientes informacionais digitais da Web como fontes de informação para a vida cotidiana. Além disso, possuem habilidades e competências construídas ao longo de suas vidas e podem utilizar o computador e a Internet para desenvolvê-las.

Uma das discussões recorrentes na Ciência da Informação é se estamos ou não vivendo em uma sociedade da informação. Se estamos, provavelmente, dentre os públicos não incluídos nesse contexto estão os idosos devido, dentre outros motivos, ao contexto sócio-econômico e cultural, bem como às dificuldades na interação humano-computador (IHC).

Nesse sentido, almejamos a inclusão dessa comunidade por meio do uso das TIC. Percebemos, por sua vez, que os conceitos de inclusão digital e inclusão social carregam na sua própria essência a problemática da exclusão. A inclusão digital e social eqüitativa pode ser ilusória, mas quando conhecemos um determinado grupo e sabemos suas características, competências e comportamentos específicos, é possível traçar caminhos e desenvolver ações considerando a inclusão como meta.

Existem inúmeras iniciativas de inclusão digital, quais sejam globais ou direcionadas para públicos específicos. Muitas delas possuem propostas viáveis para seu desenvolvimento, porém apresentam problemas no que se refere ao planejamento, o que inviabiliza a ação e, muitas vezes, com resultados contraditórios aos esperados.

Considerando o contexto brasileiro, Aun e Angelo (2007) avaliaram projetos de inclusão digital e perceberam que as maiores preocupações são direcionadas à disponibilização de tecnologias. Um exemplo disso são os telecentros distribuídos pelo país que fornecem equipamentos tecnológicos, porém carecem de pessoas capacitadas para ensinar sobre as TIC, no que diz respeito ao uso crítico das informações disponíveis nos ambientes digitais bem como à contribuição intelectual de conteúdos em ambientes colaborativos da Web 2.0.

Em contrapartida a projetos globais de inclusão, como os telecentros, podemos esperar que a investigação de uma comunidade local e de sua 
identidade cultural possibilitaria projetos de inclusão digital mais efetivos. Projetos como o 'Janelas da cultura local' de Freire (2006) se inserem nesse contexto. O resgate da memória da identidade cultural da cidade de Quissamã-RJ é o foco desse projeto que possui coordenadas de ação efetivas para a inclusão digital dessa comunidade. A autora propõe em seu projeto inicial

[...] o desenvolvimento de ações de informação, de forma participativa, com vistas a promover a competência de pessoas da comunidade em tecnologias intelectuais de informação, incluindo a construção de um hipertexto digital sobre a cultura local, que será o eixo motivacional e operatório da pesquisa. (FREIRE, 2006, p.65).

Propostas que têm como foco a inclusão digital utilizam as TIC como ferramentas que podem viabilizar $o$ desenvolvimento de habilidades $e$ competências, direcionando o indivíduo para a inclusão social. $E$ é isso que pretendemos neste trabalho, o qual visa o conhecimento de uma comunidade específica, os idosos, e a proposta de inclusão digital como uma meta possível de ser cumprida. Além disso, aproveitamos um espaço de inclusão já criado para o desenvolvimento deste trabalho, a Universidade Aberta à Terceira Idade (UNATI), um projeto de extensão universitária com o objetivo de educação continuada para a reintegração social dos idosos, valendo-se do ambiente universitário para tal.

Jordão Neto (1998, p. 41) afirma que:

[...] a criação das universidades [abertas à terceira idade] representou uma oportunidade sem igual para fazer os idosos se reencontrarem, redescobrindo o seu potencial, e se perceberem como seres humanos que podiam e deviam se valorizar como cidadãos ativos e participantes; recuperando assim sua autoestima; resgatando sua auto-imagem e mostrando aos familiares e à sociedade sua capacidade de pensar e de agir por si mesmos; sobretudo, de ir à luta pelos seus direitos e pela conquista de seu legítimo espaço social.

No Brasil, a primeira experiência de educação para a Terceira Idade foi implementada pelo Serviço Social do Comércio (SESC). Surgiu na década de 1960 com a mesma metodologia de serviço social aplicada para crianças, jovens e adultos, compreendendo basicamente as seguintes atividades: desenvolvimento físico-esportivo, recreação, turismo social, biblioteca, apresentações artísticas, cursos livres e supletivos entre outras atividades (CACHIONI, 1999).

Outras iniciativas semelhantes à do SESC surgiram no Brasil, mas grande parte não foi levada adiante. Somente a partir da década de 1980, “[...] as universidades começaram a abrir um espaço educacional, tanto para a população idosa como para profissionais interessados no estudo das questões do envelhecimento" (CACHIONI, 1999, p.161).

Nesse cenário, surgiram as UNATI da Universidade Estadual Paulista "Júlio de Mesquita Filho" (UNESP) que, segundo Cordeiro (2003), desde 1993, atuam 
espalhadas em unidades por todo o Estado de São Paulo². Vinculadas à PróReitoria de Extensão Universitária, desenvolvem atividades de ensino, pesquisa e extensão ligadas às questões de envelhecimento humano. Como são várias as unidades da UNESP, existem vários Núcleos Locais da UNATI que seguem esse regimento. A idade de ingresso dos alunos no programa pode variar de uma a outra. Como exemplo, a idade mínima para admissão na UNATI da UNESP, campus de Marília, é de 55 anos, independente do nível de escolaridade. No caso específico desta unidade, seu trabalho foi iniciado em 1995, oferecendo aos integrantes do programa as seguintes atividades: palestras, cursos de línguas, biblioterapia, informática, oficinas de teatro entre outras (CORDEIRO, 2003).

Outro programa que se destaca é a UNATI da Universidade Estadual do Rio de Janeiro (UERJ). Seu surgimento data de maio de 1992, como prosseguimento de outro projeto em andamento, o Núcleo de Assistência ao Idoso (NAl), criado no final da década de 1980. Esse programa é dividido em três áreas: ensino (educação permanente e formação; desenvolvimento de recurso humanos em geriatria e gerontologia); extensão (atendimento ambulatorial, jurídico, nutricional e do serviço social; cursos introdutórios e mais específicos em gerontologia); e pesquisa (desenvolvimento de projetos que buscam investigar aspectos variados da comunidade). Os alunos podem ingressar no programa a partir dos 60 anos independente de seu nível de escolaridade (CACHIONI, 1999).

Por meio da descrição dos programas de educação continuada para a terceira idade da UNESP e da UERJ, podemos afirmar que ambas, além de várias outras espalhadas pelo Brasil, possuem objetivos similares, tendo como principal a reintegração dos idosos na sociedade e o desenvolvimento de suas potencialidades.

Além da inclusão social, algumas UNATI se preocupam com a inclusão digital, oferecendo cursos de informática e ambientes informacionais disponíveis na Web desenvolvidos especificamente para idosos.

A UNATI da UERJ, em março de 1999, criou o Centro de Referência e Documentação sobre Envelhecimento (CRDE) que visa, sobretudo, a disponibilização de material pertinente à terceira idade. Para Prado, Amorim e Abreu (2003, p.2), os objetivos mais gerais dessa biblioteca digital são:

[...] a organização, a sistematização e a disseminação de informações, através da implementação de bases de dados que contemplem as mais diversas áreas temáticas do conteúdo gerontológico e geriátrico e do estabelecimento de vínculos com instituições afins, buscando integrar redes de informação nesse âmbito do conhecimento.

O CRDE encontra-se disponível no web site da UERJ-UNATI ${ }^{3}$, onde é possível consultar: o acervo técnico e científico do CRDE; a base de dados

\footnotetext{
${ }^{2}$ A UNESP possui vinte núcleos UNATI, que atuam nos seguintes campi: Araçatuba, Araraquara, Assis, Bauru, Botucatu, Dracena, Franca, Guaratinguetá, Ilha Solteira, Jaboticabal, Marília, Presidente Prudente, Rio Claro, Rosana, São José dos Campos, São José do Rio Preto, São Paulo (Instituto de Artes), São Paulo (Reitoria), São Vicente e Sorocaba.

3 Disponível em: <http://www.unati.uerj.br>. Acesso em: 24 set. 2010.
} 
bibliográficos referente às teses e dissertações sobre envelhecimento produzidas no Brasil, incluindo textos completos; os artigos, em versão integral, do periódico Textos sobre Envelhecimento ${ }^{4}$; as revistas científicas nacionais e internacionais sobre geriatria e gerontologia; os lançamentos editoriais da UNATI, incluindo textos completos; os programas brasileiros de pós-graduação que contam com linhas de pesquisa sobre envelhecimento humano; os grupos de pesquisa cadastrados no CNPq; e a legislação sobre idosos no Brasil (PRADO; AMORIM; ABREU, 2003).

Outro projeto que se destaca pertence à Universidade Aberta à Terceira Idade da Universidade Federal de São Paulo (UNIFESP-UATI ${ }^{5}$ ), que inaugurou o primeiro curso virtual para pessoas cuja faixa etária abrange 50 anos ou mais, incentivando o uso do computador por meio de aulas à distância.

Na UNESP - Marília são desenvolvidas pesquisas com os alunos da UNATI por alunos do Curso de Biblioteconomia e do Programa de Pós-Graduação em Ciência da Informação. Essas pesquisas enfocam as necessidades informacionais dos idosos e a identificação de elementos, recursos e serviços que podem ser implementados em ambientes informacionais da Web com vistas à inclusão digital e social desse grupo, com enfoque nos estudos de Arquitetura da Informação, Usabilidade, Acessibilidade e Comportamento Informacional. Por meio de pesquisa-ação, os próprios alunos auxiliam no planejamento e desenvolvimento de ambientes informacionais digitais. $O$ repositório digital ${ }^{6}$ da UNATI-UNESP é um exemplo. Possui, no interior da comunidade do Núcleo de Marília, uma taxonomia desenvolvida junto aos alunos com assuntos de seu interesse e também de interesse da instituição. Mais detalhes sobre esse ambiente são apresentados por Vechiato (2010). O blog Internautis ${ }^{7}$ e o twitter da UNATI - Marília ${ }^{8}$ também foram desenvolvidos tendo em vista a necessidade de trabalhar com os idosos no contexto dos ambientes colaborativos (VECHIATO, 2010; VIDOTTI et al, 2009).

As iniciativas para o uso das TIC pelos idosos possibilitam que os mesmos se sintam atraídos e queiram aprender e se familiarizar com elas. O problema é que o fato de querer vencer as barreiras pode colidir com o medo e resistência a essas tecnologias, dificultando ao idoso atingir seus objetivos. Isso já não ocorre com os jovens, os quais nasceram e aprenderam a utilizar os meios eletrônicos nessa geração e, provavelmente, não terão problemas no futuro. Garcia (2001, p.32-33) constata que

Os jovens de hoje aprendem a lidar com as novas tecnologias, acompanhando a evolução dos tempos e estão dispostos a aprender a utilizar o computador. São curiosos e com isso, aprendem com maior rapidez. O mesmo, porém, não ocorre com os idosos. Muitos sentem receio, têm medo e criam uma certa

\footnotetext{
${ }^{4}$ Cujo título foi alterado para Revista Brasileira de Geriatria e Gerontologia.

${ }^{5}$ Disponível em: <http://virtual.epm.br/uati/>. Acesso em: 24 set. 2010.

${ }^{6}$ Disponível em: <http://linuxrepositorios.marilia.unesp.br:8080/dspace/>. Acesso em: 24 set. 2010.

7 Disponível em: <http://internautis.wordpress.com/>. Acesso em: 24 set. 2010.

${ }^{8}$ Disponível em: <http://twitter.com/unati_unesp_ffc>. Acesso em: 24 set. 2010.
} 
resistência em aprender a usar a informática, por acreditarem que vão manusear o computador erroneamente ou que venham a danificá-lo.

Mesmo assim, iniciativas de inclusão digital têm obtido resultados bastante positivos, possibilitando que 0 idoso possa se inserir no ambiente digital aos poucos, desenvolvendo suas potencialidades juntamente com os outros membros do grupo com quem compartilha conhecimento e experiências de vida.

Uma outra iniciativa, além dos ambientes informacionais digitais com conteúdos específicos para idosos, a qual tem colaborado para a inclusão digital, são os cursos de informática oferecidos pelas UNATI.
É natural que as pessoas tenham resistência quando se defrontam com o que é novo. Mas a partir do momento em que se conta com uma orientação, ou seja, uma colaboração de pessoas que dominem essa novidade, a tendência é que adquiram confiança, liberando os bloqueios que existem dentro de si. (GARCIA, 2001, p.33)

A educação para a inclusão digital dos idosos deve ser cuidadosamente refletida. Portanto, os cursos de informática que as UNATI oferecem necessitam de metodologia adequada. Para Kachar (2003, p.53),

\begin{abstract}
Algumas universidades abertas para a terceira idade oferecem curso de introdução sobre os recursos do computador dentro do seu leque de opções, porém, como as pesquisas sobre o impacto da aprendizagem e utilização do computador pela terceira idade são escassas no Brasil, acredita-se que os cursos ainda não apresentem uma metodologia de ensino e aprendizagem específica para o idoso.
\end{abstract}

Nesse contexto, percebemos a necessidade de refletir sobre o ensino no âmbito dos cursos de informática da UNATI - UNESP - Campus de Marília, a partir do trabalho desenvolvido por Kachar (2003) na Pontifícia Universidade Católica de São Paulo (PUC-SP), bem como da investigação de elementos construtivistas aplicados à educação, com enfoque na mediação da informação.

\title{
3 PRÁTICA CONSTRUTIVISTA NA INCLUSÃO DIGITAL DE IDOSOS: o papel do professor-mediador na busca pela autonomia do aluno
}

A capacitação de idosos para o uso das TIC deve atuar em uma perspectiva que considere suas habilidades e competências como ponto de partida para o projeto de ensino. As teorias construtivistas trazem elementos que podem ser utilizados na prática docente nesse contexto, proporcionando ao professor-mediador o entendimento do meio em que ele atua, bem como do aluno, consciente, crítico e autônomo no processo de construção de conhecimento.

No entanto, é necessário ter uma visão crítica sobre a prática construtivista no processo de ensino-aprendizagem, pois alguns autores, como veremos adiante, reforçam que o construtivismo foi apreendido erroneamente em algumas práticas educativas, o que pode prejudicar o ensino ao invés de potencializá-lo, 
principalmente quando os elementos e características principais são desviadas do seu núcleo central.

Para Aznar Minguet (1998), o construtivismo surgiu com a crise do positivismo, que possuía características tais como: reducionista, metafísico, ausência de questionamentos, fatos concretos, realidade determinada e verdade absoluta. Desse modo, o construtivismo atua em um paradigma que traz uma nova concepção do sujeito: ativo, autoconstrutor e autônomo.

Arja Castañon (2007, p.116) lembra que a concepção filosófica que está por trás do construtivismo pode remeter à obra de Immanuel Kant:

É a inversão do sentido da relação entre sujeito e objeto que é a raiz do construtivismo. Tradicionalmente, a filosofia ocidental pensava o conhecimento como uma determinação do sujeito cognoscente pelo objeto conhecido. Kant apresenta o processo do conhecimento como a organização ativa por parte do sujeito através das estruturas da mente - do material que nos é fornecido pelos sentidos. Ou seja, para o construtivismo, o sujeito constrói suas representações de mundo, e não recebe passivamente impressões causadas pelos objetos.

Grande parte dos autores que abordam o construtivismo, como Rossler (2000), afirmam que a epistemologia genética de Jean Piaget pode ser considerada o núcleo do pensamento construtivista.

[...] poderíamos definir o construtivismo como um conjunto de diferentes vertentes teóricas que, apesar de uma aparente heterogeneidade ou diversidade de enfoques no interior de seu pensamento, possuem como núcleo de referência básica a epistemologia genética de Jean Piaget, em torno à qual são agregadas certas características que definem a identidade do ideário construtivista como um ideário filosófico, psicológico e educacional, compartilhando, assim, um mesmo conjunto de pressupostos, conceitos e princípios teóricos. (ROSSLER, 2000, p.7)

O arcabouço teórico do ideário construtivista repousa nas seguintes perspectivas apresentadas por Aznar Minguet (1998):

- Perspectiva filosófica: interação dialética do homem com seu meio; condicionamento do conhecimento a partir da experiência prévia; a assimilação $^{9}$ de objetos que podem ou não ter relações com experiências prévias, gerando omeostase $\operatorname{cognitiva}^{10}$ e acomodação $^{11}$;

\footnotetext{
${ }^{9}$ [...] integração a estruturas prévias, que podem permanecer invariáveis ou são mais ou menos modificadas por esta própria integração, mas sem descontinuidade com o estado precedente, isto é, sem serem destruídas, mas simplesmente acomodando-se à nova situação. A assimilação, definida assim em termos funcionais muito gerais, desempenha um papel necessário em todo o conhecimento. (PIAGET, 1973, p.13).

${ }^{10}$ [...] conflito que desemboca em novas realidades que não sejam comuns até que haja ajuste novas estruturas de significado. (AZNAR MINGUET, 1998).

${ }^{11}$ [...] toda modificação dos esquemas de assimilação sob a influência de situações exteriores (meio) aos quais se aplicam. Mas, assim como não há assimilação sem acomodações (anteriores ou atuais), assim também não há acomodação sem assimilação. Isto significa que o meio não
} 
organização ativa e adaptação funcional entre o conhecimento e a realidade;

- Perspectiva bioantropológica: o homem possui uma estrutura psicobiológica, tendo como características diferenciais com relação a outros seres vivos o inacabamento, a indeterminação e a abertura. Além disso, o homem possui autonomia no processo de construção do conhecimento que, para Maturana e Varela (2001), depende de sua auto-organização (autopoiese);

- Perspectiva da genética do comportamento: coexistência entre as correntes racionalista e empírica no desenvolvimento do indivíduo. Um exemplo disso é a linguagem humana que, para Morin (1999, p.133),

[...] é realmente a encruzilhada entre inato e adquirido: a aptidão à linguagem é inata no homo sapiens, mas toda língua deve ser aprendida numa cultura e toda língua permite adquirir 0 conhecimento de uma cultura.

O ideário construtivista abrange uma ampla gama de autores, sendo alguns deles Jean Piaget, que investigou os conceitos de assimilação e acomodação, baseados na experiência prévia do sujeito; Lev Semenovich Vygotsky, que desenvolveu o conceito de zona de desenvolvimento proximal; e David Ausubel, que apresenta a teoria da aprendizagem significativa, a qual permite ser trabalhada por meio da técnica de criação de mapas conceituais.

Essa ideologia chamou a atenção dos educadores e foi disseminada como um novo paradigma para o processo de ensino-aprendizagem. Porém, muitos autores como Massabni (2007) e Miranda (2000) apresentam estudos de caso que mostram alguns elementos construtivistas em práticas docentes que nem sempre são desenvolvidos de maneira eficiente. Por outro lado, é possível sugerir que nem todos os elementos construtivistas são eficazes. Cada caso é um caso e é necessário refletir sobre essas práticas.

O construtivismo é alvo de algumas críticas. Rossler (2000, p.18), por exemplo, observa que "[...] a presença da sedução na difusão e na incorporação do ideário construtivista contradiz o objetivo central por ele proclamado: a busca da autonomia intelectual e moral dos sujeitos". Essa sedução gera, segundo o autor, a manipulação ideológica que desencadeia uma série de práticas incorretas que se autojustificam como construtivistas.

Arce (2000) reforça a discussão crítica na aproximação ideológica dos conceitos construtivistas, neoliberais e pós-modernistas iniciada por Newton Duarte no livro Vygotski e o "aprender a aprender": crítica às apropriações neoliberais e pós-modernas da teoria vigotskiana. Analisamos, portanto, uma das características trazidas pela autora, baseada no ideário construtivista: "O ensino e a escola devem levar o aluno a "aprender a aprender". Sua realidade e seu

provoca simplesmente o registro de impressões ou a formação de cópias, mas desencadeia ajustamentos ativos. É por isso que só falamos em 'acomodação' subtendendo 'acomodação de esquemas de assimilação'. (PIAGET, 1973, p.18). 
cotidiano são as referências. Conteúdos devem ser reduzidos aos que puderem ser realmente compreendidos pelos alunos" (ARCE, 2000, p.51).

Percebemos que essa característica indica que o conteúdo é limitado à experiência do aluno. É claro que isso pode ser usado como ponto de partida para um bom aprendizado, bem como torna o professor mais interado e consciente da vida cotidiana dos alunos. O problema está na apropriação desse elemento como sendo o ponto final, a última instância, limitando o universo do aluno e extinguindo-lhe as diversas possibilidades, além de reduzir o papel do professor e o próprio conceito de mediação.

A autora ressalta que

[...] o construtivismo, alicerçado nas discussões pós-modernas, pode afirmar de modo categórico que a educação escolar deve ter como fonte principal do processo de ensino-aprendizagem a construção individual do conhecimento, a negociação de significados, centrando no cotidiano os conteúdos, não falando em privação cultural mas em diferenças culturais, assim como o discurso neoliberal não fala em exploração econômica mas em diferenças econômicas saudáveis, frutos da competitividade do mercado (ARCE, 2000, p.52).

Nessa relação com o neoliberalismo, Arce trata de um aspecto bastante importante: a privação cultural. A prática construtivista não deve privar as pessoas de novos conhecimentos ou limitar a construção do conhecimento aos alunos. Nesse sentido, o professor não tem seu papel reduzido quando atua como mediador.

Tendo em vista o processo de mediação visando à autonomia do aluno, baseando-se criticamente em elementos construtivistas, retomamos a Ciência da Informação e a proposta de capacitação de idosos para o uso das TIC. Nesse contexto, cabe o conceito de mediação da informação de Almeida Júnior (2008, p.46):

Mediação da informação é toda ação de interferência - realizada pelo profissional da informação - direta ou indireta; consciente ou inconsciente; singular ou plural; individual ou coletiva; que propicia a apropriação de informação que satisfaça, plena ou parcialmente, uma necessidade informacional.

O autor ressalta que existe uma linha tênue entre interferência e manipulação. No contexto do construtivismo, sua prática "sedutora" e incoerente com seus próprios propósitos pode direcionar a interferência no sentido de um discurso manipulado, podendo direcionar também o compartilhamento de conhecimento à mera transferência de conhecimento.

Essa problemática pode ser identificada em cursos de informática tradicionais. Normalmente, as escolas de informática possuem metodologias diferenciadas para crianças e jovens. Para adultos e idosos é utilizada a mesma metodologia. Isso não deve ocorrer, pois o contexto social em que esses grupos estão inseridos é bastante diferente. O primeiro grupo é ou quer estar extremamente ativo no mercado de trabalho, por isso busca esses cursos. $O$ segundo grupo, por sua vez, procura aulas de informática com necessidades 
específicas, como se comunicar com os filhos, compartilhar receitas, ler poesias, digitar textos e buscar informações sobre saúde entre outros assuntos disponíveis na Web etc.

Como explicitado, Vitória Kachar (2003) realizou uma investigação com alunos da UNATI da PUC-SP nessa perspectiva de capacitação de idosos para o uso das TIC. Em seu livro Terceira idade e informática: aprender revelando potencialidades, é perceptível o uso coerente de elementos construtivistas em sua prática de ensino.

Primeiramente, Kachar (2003) comenta sobre a necessidade da construção de um ambiente educacional interdisciplinar, em que possa haver trocas entre 0 professor e os alunos, além da exploração do computador pelos alunos apenas como uma ferramenta, em que poderão realizar diversas atividades e desenvolver competências.

O ambiente educacional é interdisciplinar, construído para a terceira idade aprender a Informática e, para além da apropriação da linguagem e domínio operacional, demonstrar seu potencial de produção, reconstruir sua auto-imagem e imagem pública, exercitando a cidadania (KACHAR, 2003, p.129).

Para propiciar a criação desse ambiente, a autora considera necessária a re-elaboração contínua da metodologia ou mesmo de toda a proposta de ensino desenvolvida, pois, com o tempo, as necessidades dos alunos podem mudar, bem como de todo o ambiente educacional. Essas necessidades de mudanças devem ser percebidas imediatamente e, para isso, Kachar (2003) atenta sobre a importância de observar e registrar tudo o que transcorrer nesse ambiente educacional em relação aos alunos, aos professores e às estratégias de aula.

A partir das abordagens investigadas, sistematizamos na Figura 1 alguns conceitos que podem ser trabalhados na perspectiva de cursos de informática para idosos visando sua inclusão digital.

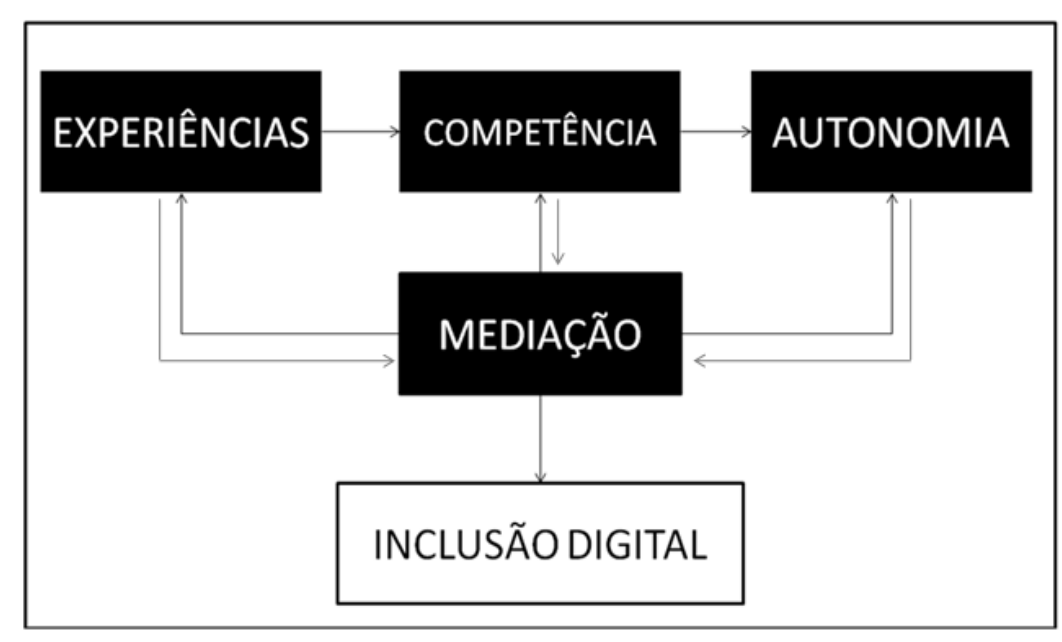

Figura 1 Processo de inclusão digital em cursos de informática para idosos. Fonte: Elaborada pelos autores. 
Esse esboço inicial do processo de inclusão digital apresenta a mediação atuando primeiramente na identificação das habilidades, potencialidades $e$ experiências dos idosos, pois é a partir delas que o professor-mediador vai traçar e elaborar um plano de ensino para a capacitação desses indivíduos.

Em um segundo momento, busca-se competência para o uso das TIC's. O conceito de competência, por si só, não abarca a complexidade da ação de aprender, muito menos finaliza o processo de ensino-aprendizagem. Pensar em competência e almejá-la, tendo em vista a capacitação de idosos, reflete na apresentação de um mundo novo pelo professor-mediador, repleto de possibilidades. Porém, é preciso esclarecer que esse mundo novo apenas facilita aquelas ações que eles sempre realizaram. Por isso, investigar as habilidades e potencialidades dos idosos pode direcionar 0 ensino das ferramentas tecnológicas.

A autonomia, que aparece ao final do processo, representa o direcionamento da competência para o uso crítico da informação e dos aparatos tecnológicos, propiciando atingir a meta de inclusão digital desse grupo específico.

Essa figura também pretende mostrar que o papel do professor-mediador é extremamente importante, visto que é ele quem interferirá diretamente em todos os momentos do processo, contribuindo para que o sujeito se auto-organize e perceba todas as ações que ele pode realizar utilizando as TIC.

\section{CURSOS DE INFORMÁTICA OFERECIDOS PELA UNATI - UNESP - CAMPUS DE MARÍLIA}

Os cursos de informática para a UNATI - UNESP - Campus de Marília começaram efetivamente a ser oferecidos em 2004 pelo Programa de Educação Tutorial (PET) de Biblioteconomia, coordenado, naquele momento, pela Profa. Dra. Silvana Aparecida Borsetti Gregorio Vidotti. A partir de 2006, ministramos um curso de informática para um pequeno grupo de alunos da UNATI que já utilizava computador e Internet. As aulas foram direcionadas ao projeto de pesquisa "Arquitetura da Informação de web sites", financiado pelo Programa Institucional de Bolsas de Iniciação Científica do Conselho Nacional de Desenvolvimento Científico e Tecnológico (PIBIC/CNPq). Até o final do ano de 2007, os alunos auxiliaram na avaliação da usabilidade de ambientes informacionais específicos para idosos. Os resultados apontaram que, nesses ambientes, há disponibilização de conteúdos relevantes para esse público, porém suas interfaces não são facilmente intuitivas e não apresentaram elementos de usabilidade e acessibilidade coerentes com as condições físicas e cognitivas específicas a esse público (VECHIATO; VIDOTTI, 2008).

Em 2008, foram oferecidos dois cursos com o objetivo de atrair um número maior de alunos: Formas de comunicação na Internet, para alunos iniciantes, objetivando introduzi-los às diversas possibilidades oferecidas pela informática e, em especial, pela Internet; e Ambientes informacionais digitais: enfoque dos web sites e repositórios, como possibilidade de complemento aos estudos dos alunos 
que fizeram os cursos nos anos anteriores e que auxiliam na avaliação de ambientes informacionais digitais para idosos. Cada curso foi oferecido uma vez por semana pelo período de duas horas.

Nos anos 2009 e 2010, mantivemos o curso Formas de comunicação na Internet e substituímos o segundo curso de 2008 pelo curso de Tecnologias de Informação e Comunicação com enfoque aos ambientes colaborativos, visando a discussão e a investigação de ambientes informacionais digitais que possibilitam a colaboração das pessoas com conteúdos intelectuais na Web 2.0.

O número de interessados nesses cursos aumentou consideravelmente entre 2008 e 2010. Portanto, foi necessário refletir em como o ensino a esse público era direcionado. Apresentamos no Quadro 1 os elementos construtivistas aplicados à educação com base em Miranda (2000), bem como as práticas vivenciadas no curso de informática até então, de acordo e relacionadas com esses elementos.

A identificação desses elementos propiciou o questionamento sobre a prática docente no contexto da inclusão digital de idosos. A partir das reflexões, observamos que nem todos os elementos apresentados podem ser seguidos à risca e tudo depende do contexto e do público que está sendo investigado.

A capacitação de um determinado público para o uso das TIC, bem como para busca e uso de informações relevantes no ambiente digital, é objeto de estudo do profissional da informação em sua atuação como mediador. Nesse contexto, investigar e educar os idosos são ações que podem culminar em sua inclusão digital e social, o que possibilita a esse profissional atuar de forma coerente na sociedade.

\begin{tabular}{|c|c|}
\hline $\begin{array}{l}\text { Elementos do construtivismo } \\
\text { aplicados à educação }\end{array}$ & $\begin{array}{l}\text { Reflexão da prática de elementos construtivistas } \\
\text { nos cursos de informática da UNATI - UNESP - } \\
\text { Campus de Marília }\end{array}$ \\
\hline $\begin{array}{l}\text { Maior autonomia do aluno em seu } \\
\text { processo de aquisição de } \\
\text { conhecimento e de socialização. }\end{array}$ & $\begin{array}{l}\text { A conquista pela autonomia do aluno idoso no uso das } \\
\text { TIC não é uma tarefa fácil. Normalmente, se apegam } \\
\text { muito à ferramenta tecnológica e como finalizar os } \\
\text { processos, mas se esquecem das verdadeiras } \\
\text { possibilidades, bem como que poderiam, em um } \\
\text { processo investigativo, agir com maior autonomia em } \\
\text { suas ações com a informática. Nesse sentido, cabe ao } \\
\text { professor-mediador a tarefa de despertar esse senso de } \\
\text { autonomia, porém é pré-requisito que os alunos } \\
\text { também explorem o que aprenderam fora do período de } \\
\text { aula o que, muitas vezes, não ocorre. }\end{array}$ \\
\hline $\begin{array}{l}\text { Maior interatividade na relação } \\
\text { sujeito-objeto, expressa na relação } \\
\text { do aluno com o meio, mediado pelo } \\
\text { professor. }\end{array}$ & $\begin{array}{l}\text { As experiências dos alunos e suas necessidades } \\
\text { direcionam as relações entre eles e o meio. O } \\
\text { compartilhamento das experiências permite } \\
\text { enriquecimento das aulas, e as atividades com } \\
\text { computador atuam diante dessas perspectivas. }\end{array}$ \\
\hline \multicolumn{2}{|c|}{$\begin{array}{l}\text { Quadro } 1 \text { uso de elementos construtivistas em projeto de ação para inclusão } \\
\text { digital: capacitação de idosos para o uso das tecnologias de informação e } \\
\text { comunicação (TIC). } \\
\text { Fonte: Elaborada pelos autores, baseada em Miranda (2000). }\end{array}$} \\
\hline
\end{tabular}




\section{Elementos do construtivismo aplicados à educação}

Efetiva valorização do processo de aprendizagem, pelo qual a significação dos conteúdos para os alunos se sobreporia a outros critérios de seleção dos mesmos (quantidade, abrangência, relevância social e cultural).

Maior dinamismo na atuação do professor que, desobrigado dos afazeres tradicionais na sala de aula, teria oportunidade de ser mais construtivo, mais reflexivo, um verdadeiro "pesquisador", pois, afinal, ele deverá ser sempre e cada vez mais um aprendiz, um construtor do próprio conhecimento. que seria mais processual, mais interativa e mais consistente, valorizando-se o erro como parte constitutiva e imprescindível do processo de aprendizagem.
Mudança no processo de avaliação,
Diferenciação do processo de socialização do aluno, que seria estimulado a ser mais cooperativo e interativo com os colegas, respondendo adaptativamente às demandas imediatas do mundo em constante transformação, transformando-se, portanto, a noção de disciplina na escola.

\section{Reflexão da prática de elementos construtivistas nos cursos de informática da UNATI - UNESP - Campus de Marília}

Os conteúdos ministrados são baseados nas experiências, no entanto busca-se respaldo teórico e empírico para identificar as necessidades específicas desse grupo etário, o que permite que o conteúdo não seja limitado apenas às experiências. Para o uso da ferramenta tecnológica, é necessário que conteúdos mais específicos da informática sejam trabalhados, objetivando o domínio da ferramenta pelos alunos.

Para Paulo Freire (2008, p.23), "quem ensina aprende ao ensinar e quem aprende ensina ao aprender". Nesse sentido, considerando o paradigma construtivista, o professor assume realmente um novo papel, mas isso precisa ser cuidadosamente e criticamente refletido como comentado anteriormente. Com certeza, entender o meio em que atua e se especializar cada vez mais são tarefas desse mediador.

As teorias construtivistas, com suas bases psicológicas, permitem que 0 indivíduo e seus erros sejam reconhecidos. Se o plano de ensino foi elaborado a partir da experiência dos alunos e se as aulas apontam para um desenvolvimento evolutivo, alguns erros advindos em certos momentos podem indicar a necessidade de avaliação do aluno e do ambiente educacional. Os alunos idosos costumam esquecer alguns procedimentos para o cumprimento de tarefas. Determinados conteúdos precisaram ser retrabalhados, pois alguns alunos faltavam às aulas e outros realmente esqueciam do que haviam aprendido. Cabe ao professor-mediador aplicar algumas medidas que conscientizem os alunos com relação a faltas desnecessárias e esclarecer a importância de explorarem o que aprenderam em suas casas e, para aqueles que possuem limitações tecnológicas, a própria UNATI oferece computadores para que os alunos possam utilizar.

Uma outra característica importante desse grupo é a ansiedade. Eles sabem o que é possível fazer, mas querem ir além da tecnologia. Isso é um ponto bastante interessante e absolutamente normal, porém é importante que entendam os procedimentos para que possam ter autonomia no momento de uso da tecnologia. Além disso, trocam experiências, conversam, mas o professor-mediador precisa às vezes intervir, pois alguns alunos não conseguem esperar os outros que possuem maiores dificuldades ou às vezes divagam em assuntos que fogem ao foco da aula. Cabe ao professor-mediador limitar algumas situações para que o foco não seja perdido.

Quadro 1 (continuação) O uso de elementos construtivistas em projeto de ação para inclusão digital: capacitação de idosos para o uso das tecnologias de informação e comunicação (TIC).

Fonte: Elaborada pelos autores, baseada em Miranda (2000). 


\begin{tabular}{|c|c|}
\hline $\begin{array}{l}\text { Elementos do construtivismo } \\
\text { aplicados à educação }\end{array}$ & $\begin{array}{l}\text { Reflexão da prática de elementos construtivistas } \\
\text { nos cursos de informática da UNATI - UNESP - } \\
\text { Campus de Marília }\end{array}$ \\
\hline $\begin{array}{l}\text { Modificação na atuação do } \\
\text { professor, que não mais seria } \\
\text { "autoritário" e sim "democrático", } \\
\text { aberto ao diálogo com os alunos, } \\
\text { que passariam a intervir } \\
\text { decisivamente nos processos de } \\
\text { decisão. }\end{array}$ & $\begin{array}{l}\text { É fácil ser autoritário e é fácil ser democrático. Difícil é } \\
\text { trabalhar as duas características simultaneamente. } \\
\text { Portanto, é preciso limitar situações e desencadear } \\
\text { outras, trabalhar de maneira efetiva o tempo de aula e } \\
\text { criar uma linha de desenvolvimento para que os alunos } \\
\text { percebam a introdução e a conclusão de conteúdos, } \\
\text { proporcionando uma construção de conhecimento } \\
\text { linear, evolutiva e coerente, de acordo com suas } \\
\text { necessidades }\end{array}$ \\
\hline $\begin{array}{l}\text { Uma sala de aula menos ordeira e } \\
\text { silenciosa, em que têm lugar a } \\
\text { experimentação, a espontaneidade, } \\
\text { o ruído e a inquietação do aluno. }\end{array}$ & $\begin{array}{l}\text { partilhamento entre os alunos ocorre tanto nas } \\
\text { s̃es orais dos professores quanto nas atividades } \\
\text { s, possibilitando sua participação ativa em todos } \\
\text { nentos. }\end{array}$ \\
\hline $\begin{array}{l}\text { Um ambiente escolar adequado aos } \\
\text { desafios da revolução informacional, } \\
\text { mais propício ao desenvolvimento } \\
\text { do chamado "novo paradigma do } \\
\text { conhecimento". }\end{array}$ & $\begin{array}{l}\text { De certo modo, isso ocorre desde a proposta inicial do } \\
\text { curso de informática. Porém, seria interessante acoplar } \\
\text { a essas aulas a leitura e discussão de textos que tratam } \\
\text { do envelhecimento humano e também da relação entre } \\
\text { os alunos e a informática, visto que os alunos precisam } \\
\text { sempre repensar e reanalisar os motivos que os } \\
\text { levaram a conhecer e investigar as TIC. }\end{array}$ \\
\hline
\end{tabular}

Quadro 1 (continuação) O uso de elementos construtivistas em projeto de ação para inclusão digital: capacitação de idosos para o uso das tecnologias de informação e comunicação (TIC).

Fonte: Elaborada pelos autores, baseada em Miranda (2000).

\section{CONSIDERAÇÕES FINAIS}

Neste trabalho, são apresentados os benefícios do uso das TIC pelos idosos. Porém, como existem dificuldades para a inclusão desse grupo no mundo digital, é necessário o conhecimento dele para a criação de projetos de capacitação que direcionem os idosos ao uso crítico das ferramentas tecnológicas e das informações disponibilizadas em ambientes informacionais digitais da Web.

Desse modo, esses sujeitos precisam atuar de maneira autônoma e, portanto, buscamos elementos no construtivismo aplicados à educação que facilitem as perspectivas do ensino de informática para a UNATI - UNESP Campus de Marília.

A investigação dos elementos construtivistas possibilitou a reflexão da prática docente no contexto dos cursos de informática para idosos oferecidos até o momento, bem como permitiu repensar algumas estratégias de ensino desenvolvidas e trabalhadas no ano de 2010.

Sugerimos que essa atividade sistematizada de ensino das TIC para idosos poderia ser repensada também com enfoque em outros públicos e ser considerada principalmente por cursos de Graduação em Biblioteconomia como um estágio curricular ou extracurricular, visto que envolve a geração, mobilização e potencialização de competências informacionais nos indivíduos e novos campos de atuação, ensino e pesquisa aos alunos envolvidos. 


\section{AGRADECIMENTOS}

Aos queridos alunos da UNATI - Marília; aos pesquisadores envolvidos no projeto "Inclusão Digital dos alunos da Universidade Aberta à Terceira Idade - UNATI / UNESP Marília" ; à FAPESP e à CAPES pelo apoio financeiro concedido; e à Profa. Dra. Maria Candida Soares Del Masso, coordenadora do Núcleo Central da UNATI - UNESP, pela participação nas discussões e reflexões apresentadas neste texto.

\section{REFERÊNCIAS}

ALMEIDA JÚNIOR, O. F. Mediação da informação: ampliando o conceito de disseminação. In: VALENTIM, M. L. P. (Org.). Gestão da informação e do conhecimento no âmbito da Ciência da Informação. São Paulo: Polis: Cultura Acadêmica, 2008. p. 41-54

ARCE, A. A formação de professores sob a ótica construtivista: primeiras aproximações e alguns questionamentos. In: DUARTE, N. (Org.). Sobre o construtivismo: contribuições a uma análise crítica. Campinas: Autores Associados, 2000. p. 41-62

ARJA CASTAÑON, G. Construtivismo, inatismo e realismo: compatíveis e complementares. Ciências \& Cognição, Rio de Janeiro, v. 10, p. 115-131, 2007. Disponível em: <http://www.cienciasecognicao.org/pdf/v10/m346131.pdf>. Acesso em: 24 set. 2010.

AUN, M. P.; ANGELO, E. S. Observatório da inclusão digital. In: AUN, M. P. (Coord.). Observatório da inclusão digital: descrição e avaliação dos indicadores adotados nos programas governamentais de infoinclusão. Belo Horizonte: Gráfica Orion, 2007. p. 63-105.

AZNAR MINGUET, P. O construtivismo na educação. In: (Org.). $A$ construção do conhecimento na educação. Porto Alegre: ArtMed, 1998. p. 11-50.

CACHIONI, M. Universidade da terceira idade: das origens à experiência brasileira. In: NERI, A. L.; DEBERT, G. G. (Org.). Velhice e sociedade. Campinas: Papirus, 1999. p. 141-178.

CALDAS, C. P. Introdução à gerontologia. In: VERAS, R.; LOURENÇO, R. (Ed.). Formação humana em geriatria e gerontologia: uma perspectiva interdisciplinar. Rio de Janeiro: UNATI UERJ, 2006. p. 18-21.

CORDEIRO, A. P. Oficinas de teatro da UNATI (Universidade Aberta à 3. Idade)UNESP de Marília: a arte e o lúdico como elementos libertadores dos processos de criação da pessoa idosa. 2003. 247f. Tese (Doutorado em Educação)Faculdade de Filosofia e Ciências, Universidade Estadual Paulista, Marília, 2003. 
FREIRE, I. M. Acesso à informação e identidade cultural: entre o global e o local. Ciência da Informação, Brasília, v. 35, n. 2, p. 58-67, maio/ago. 2006. Disponível em: <www.scielo.br/pdf/ci/v35n2/a07v35n2.pdf>. Acesso em 24 set. 2010.

FREIRE, P. Pedagogia da autonomia: saberes necessários à prática educativa. 37. ed. São Paulo: Paz e Terra, 2008.

GARCIA, H. D. A terceira idade e a internet: uma questão para o novo milênio. 2001. 171f. Dissertação (Mestrado em Ciência da Informação)- Faculdade de Filosofia e Ciências, Universidade Estadual Paulista, Marília, 2001. Disponível em: <http://www.marilia.unesp.br/Home/Pos-Graduacao/Cienciadalnformacao/Disser tacoes/dominguez_garcia_me_mar.pdf >. Acesso em 24 set. 2010.

JORDÃO NETO, A. A universidade aberta para a terceira idade da PUC-SP. A Terceira ldade, São Paulo, v. 10, n. 14, p. 39-43, ago. 1998.

KACHAR, V. Terceira idade e informática: aprender revelando potencialidades. São Paulo: Cortez, 2003.

MASSABNI, V. G. O construtivismo na prática de professores de ciências: realidade ou utopia? Ciências \& Cognição, Rio de Janeiro, v.10, p.104-114, 2007. Disponível em: <http://www.cienciasecognicao.org/pdf/v10/m346129.pdf>. Acesso em 24 set. 2010.

MATURANA, H. R.; VARELA, F. J. A árvore do conhecimento: as bases biológicas da compreensão humana. São Paulo: Palas Athena, 2001

MIRANDA, M. G. Pedagogias psicológicas e reforma educacional. In: DUARTE, N. (Org.). Sobre o construtivismo: contribuições a uma análise crítica. Campinas: Autores Associados, 2000. p. 23-40.

MORIN, E. O método 3: o conhecimento do conhecimento. Porto Alegre: Sulina, 1999.

PIAGET, J. Biologia e conhecimento: ensaio sobre as relações entre as regulações orgânicas e os processos cognoscitivos. Petrópolis: Vozes, 1973.

PRADO, S. D.; AMORIM, A. E.; ABREU, C. R. Centro de referência e documentação sobre envelhecimento UNATI-UERJ: identificação, sistematização e disseminação de informações sobre envelhecimento humano no Brasil. Textos Sobre Envelhecimento, Rio de Janeiro, v. 6, n.1, 2003. Disponível em: <http://www.unati.uerj.br/>. Acesso em: 04 nov. 2009.

ROSSLER, J. H. Construtivismo e alienação: as origens do poder de atração do ideário construtivista. In: DUARTE, N. (Org.). Sobre o construtivismo: contribuições a uma análise crítica. Campinas: Autores Associados, 2000. p. 3-22.

VECHIATO, F. L. Repositório digital como ambiente de inclusão digital e social para usuários idosos. 2010. 183f. Dissertação (Mestrado em Ciência da Informação)- Faculdade de Filosofia e Ciências, Universidade Estadual Paulista, 
Marília, 2010. Disponível em: <http://www.marilia.unesp.br/Home/PosGraduacao/Cienciadalnformacao/Dissertacoes/vechiato_fl_me_mar.pdf>. Acesso em: 24 set. 2010.

; VIDOTTI, S. A. B. G. Avaliação da usabilidade de ambientes informacionais digitais sobre envelhecimento humano no contexto da arquitetura da informação: aplicação de avaliação heurística e testes de usabilidade com usuários idosos. In: ENCONTRO NACIONAL DE PESQUISA EM CIÊNCIA DA INFORMAÇÃO, 9, 2008, São Paulo. Anais... São Paulo: ANCIB, 2008, p.1-13.

VIDOTTI, S. A. B. G.et al. Inclusão digital para os alunos da UNATI UNESP/Marília. Revista Ciência em Extensão, São Paulo, v. 5, n. 2, p. 42-59, 2009. Disponível em: <http://ojs.unesp.br/index.php/revista_proex/article/view/ 287>. Acesso em: 18 jul. 2010.

WHITAKER, D. C. A. Envelhecimento e poder: a posição do idoso na contemporaneidade. Campinas: Alínea, 2007.

\section{Title}

Contributions of constructivism elements and of information mediation to the digital inclusion for elderly

\section{Abstract}

The life expectancy increase has been augmenting studies on human aging. Among these studies are those that address the interaction between the elderly and the information and communication technologies, which may facilitate the execution of daily activities by elderly people. Therefore, the goal of this article was to investigate the application of constructivist elements in computer courses offered to Universidade Aberta à Terceira Idade - UNATI - UNESP - Campus of Marilia, contributing to the digital inclusion of this community. The constructivist elements focused on the role of the teacher as a mediator in the teaching-learning process. It was found that most of these elements are already being applied in this universe, but some changes need to be undertaken in order to expand the opportunities for education and to allow students to have more autonomy for information seeking and use in the web environment.

\section{Keywords}

Digital Inclusion. Elderly People. Constructivism. Information and Communication Technologies. Information Mediation...

\section{Título}


Contribuciones de los elementos del constructivismo y de la mediación de información para la inclusión digital de personas mayores

\section{Resumen}

Con el aumento de la expectativa de vida de la población mundial, los estudios sobre el envejecimiento humano están creciendo considerablemente. Entre estos estudios, se destaca la interacción entre las personas mayores y las tecnologías de la información y de la comunicación, las cuales pueden facilitar la realización de las actividades cotidianas de estas personas. En este sentido, se investiga la aplicación de elementos constructivistas en los cursos de informática ofrecidos por la Universidade Aberta à Terceira ldade - UNATI - UNESP - Marília, contribuyendo a la inclusión digital de esta comunidad. Estos elementos se reflejan, centrándose en el papel del profesor-mediador en el proceso de enseñanza y aprendizaje. Se encontró que la mayoría de los elementos constructivistas son aplicados en este universo, pero algunos cambios deben llevarse a cabo con el fin de ampliar las posibilidades de la enseñanza y permitir a los estudiantes tener una mayor autonomía en la búsqueda y utilización de información en la Web.

\section{Palabras clave}

Inclusión Digital. Ancianos. Personas Mayores. Constructivismo. Tecnologías de Información y Comunicación. Mediación de Información.

Recebido em: 05/10/2010

Aceito em: 17/01/2011 